\title{
A participação do corpo nas experiências artísticas digitais
}

Ângela Marques

\section{Resumo:}

Este artigo pretende mostrar que a participação do corpo nas experiências artísticas digitais requer uma redefinição da problematização da experiência estética mediada pela tecnologia. Argumentamos que esta última está ligada à descoberta e à reconfiguração do corpo em sua constante experimentação do mundo, de si mesmo e do outro. Nosso objetivo é apresentar, no contexto de experiências artísticas que utilizam instrumentos tecnológicos, algumas interações entre corpo/máquina e corpo/objetos mediadores que podem contribuír para a criação de experiências estéticas tecnologicamente mediadas. Tais dinâmicas são capazes de transformar o corpo (suas imagens, sensações e movimentos) em possibilidades de atualização dos modos de nos transformarmos e de conhecermos o mundo e os outros.

\section{Palavras Chave:}

corpo, experiência estética, arte tecnológica, virtual

\begin{abstract}
:
The aim of this article is to show that the participation of the body in digital artistic experiences requires a redefinition of the problematic concerning aesthetic experience mediated by technology. We argue that aesthetic experience is related to the discovery and reconfiguration of the body in its constant experimentation of the world, of itself and of the other. Our objective is to present, in the context of artistic experiences using technological instruments, some body/machine and body/mediating objects interactions that can contribute for the creation of aesthetic experiences technologically mediated. Such dynamics are capable to transform the body (its images, sensations and movements) into possibilities of updating the ways in which we transform ourselves and discover the world and the others.
\end{abstract}

\section{Keywords:}

body, aesthetic experience, technological art, virtual

\section{Introdução}

Em que consiste a virtualização do corpo? Em sua desmaterialização? Ou os instrumentos tecnológicos apenas possibilitaram que o corpo mudasse de "casca" e, assim, tivesse sua percepção ampliada? A artista multimídia Diana Domingues (1997) afirma que as novas tecnologias redimensionam o corpo em suas atividades performáticas e sensíveis. Por sua vez, Pierre Lévy (1996) acredita na perseguição do corpo espectral, sem gravidade, vestígios, viscosidade e aderência. Em contrapartida, Roy Ascott (2000) - que também se refere ao processo de amplificação do corpo por meio de sua virtualização - afirma que se nós deixamos o nosso velho corpo clássico e terrestre, não é para nos desmaterializar, mas antes para habitar uma nova realidade corporal que é o produto de um profundo desejo humano de transcendência: estar fora do corpo, fora da mente, para além da linguagem.

Com o computador, e unificados pelo envolvimento telemático, podemos ter esperança de ver de relance o que não pode ser visto, de compreender o caos inefável do 'tornar-se', a ordem secreta 
da desordem. E, na medida em que vemos mais, deveremos ver cada vez menos o computador. Ele se tornará invisível em sua imanência, mas sua presença sera palpável para o artista engajado telematicamente no processo mundial de autopoiesis. (ASCOTT, 1990: 247)

O fato é que antes mesmo das novas tecnologias da comunicação despertarem tantos questionamentos acerca da mutabilidade do corpo, já enfrentávamos o fetiche da estética. Couto (1999) aponta a necessidade que os sujeitos possuem de se auto-recriarem, apropriando-se dos modelos corporais que circulam na mídia. Agindo dessa forma, esses sujeitos se constróem incessantemente como "matrizes e sombras" que podem vir a ser modelos para outros sujeitos desejantes de um corpo perfeito, pois é preciso atualizar o corpo de acordo com uma imagem-matriz amplamente aceita e reivindicada.

O que nos cabe pontuar é que um corpo virtualizado não traz à tona só a matriz que o constitui, mas sim abre um campo de possibilidades para que o corpo sofra agenciamentos de ordem criativa. A tentativa de copiar um corpo esbelto estampado na mídia, a incorporação de aspectos maquínicos ao corpo humano, o contato telemático com o outro, enfim, o diálogo com a máquina e a projeção do corpo virtual só adquirem sentido se pensarmos em uma experiência estética capaz de, ao mesmo tempo, valorizar a subjetividade - a singularidade de cada indivíduo - e a transformação dos contatos do indivíduo com o mundo e com os outros. Nesse sentido, as formas artísticas digitais não estão mais centradas na aparência, na concretude sígnica, mas sim permitem-nos viver eventos, experimentar acontecimentos que se processam no intercâmbio bilateral entre virtual/real; digital/analógico; corpo/máquina; material/imaterial; sensível/inteligível.

O estudo da experiência estética, enquanto processo comunicativo que envolve o auto-descobrimento e a revelação do universo do outro, confere importância e destaque às mediações que estruturam nossas experiências pessoais, nossas relações com os outros e com o mundo concreto (GUIMARÃES e FRANÇA, 2006). Como afirma Guimarães (2002a), a experiência é relacional, ela marca maneiras e possibilidades de compartilhar, de dialogar e de instaurar "passagens" entre diferenças e outros modos de experimentar o mundo. Jean Caune (1997) afirma que a experiência estética é da ordem da transformação, uma vez que ela modifica o sujeito, suas relações com mundo, com a cultura e com os outros através de uma constante recomposição de narrativas e códigos culturais. Partindo do princípio de que a experiência estética é uma fonte de descobertas e de intervenções sobre o mundo e sobre si mesmo, ela guarda a potencialidade de modificar aqueles que dela tomam parte. Todavia, esse potencial de mudança só se concretiza mediante a confrontação dos sujeitos com o outro, com um texto, uma obra de arte, um acontecimento ou uma situação, seja permitindo-lhes se manter no limite do conhecido, seja reconfigurando suas atitudes e formas de compreender o mundo (GUIMARÃES, 2002a). E, nesse confronto, estabelece um diálogo, uma interpelação recíproca que instaura novas possibilidades de compreensão, interpretação e conhecimento da individualidade e da alteridade.

Por isso, concordamos com a definição apresentada por Caune (1997) para a experiência estética, distinguindo quatro componentes principais desse processo: a) a auto-compreensão dos sujeitos; b) a experiência da relação com o outro; c) os vínculos com a cultura e com os enunciados que constróem a relação social; e d) o projeto de auto-construção e de construção cultural a longo prazo. Essas dimensões podem nos ser úteis para indicarmos algumas das modalidades de intervenção maquínica no corpo e/ou de suas reivindicações enquanto elementos centrais da eperiência estética mediada tecnologicamente.

No que se refere à auto-compreensão dos sujeitos, a experiência estética deve ser entendida como uma ação reflexiva que coloca em jogo a totalidade do sujeito, conduzindo-o, constantemente a um retorno sobre si mesmo (CAUNE, 1997: 21). O segundo aspecto destacado por Caune nos remete ao fato de que a experiência estética não é somente uma experiência individual, mas uma experiência capaz de religar o sujeito ao mundo em que vive, bem como de devolvê-lo à dimensão da alteridade. Já a terceira 
componente acima mencionada aponta para o fato de que a experiência estética não é nunca imediata, mas faz parte das enunciações que constroem a relação social. Ela se serve do que é familiar (dos universos de sentidos partilhados intersubjetivamente) para nos apresentar algo "desconhecido". É preciso ressaltar que o quadro de sentidos partilhado, o qual nos permite uma compreensão mútua sobre algo no mundo, se encontra intrinsecamente ligado aos dispositivos de produção e de difusão dos objetos culturais. Por fim, a quarta componente remete-se à noção de experiência estética como um projeto, e isso vale tanto para as manifestações que ela utiliza (e que garantem sua concretude) quanto para a interpretação que ela implica.

A experiência estética diz, portanto, da auto-construção identitária dos sujeitos, de seu encontro com o mundo e com o outro, reforçando e reconstruindo o pano de fundo cultural que estrutura suas relações. Processos de virtualização do corpo expressam, assim, não só desejos individuais, mas um movimento cultural, social e estético de transformação das condições das experiências cotidianas, que devem ser intensificadas não só no âmbito do sujeito, mas também no âmbito de suas relações intersubjetivas.

Neste artigo, partimos do pressuposto de que, ao ser virtualizado, o corpo é lançado num campo problemático, do qual só emerge através de um acontecimento propiciado por uma atualização. Nesse sentido, o corpo espectral - em constante busca de novas realizações, atualizações, metamorfoses - se torna modelo potencializado e potencializador, uma vez que gera imagens-sombra, as quais "desejam" colar-se aos indivíduos ávidos por perfeição e potência. No entanto, essa potência (empregada na confecção do corpo-prótese) está dissociada da criatividade, pois busca a imitação, a mímese e a despotencialização da imagem. Diante disso, nosso objetivo é apresentar, no contexto de experiências artísticas que utilizam instrumentos tecnológicos, algumas dinâmicas dialógicas entre corpo-máquina e corpo-objetos mediadores que podem contribuír para a criação (poiésis) de formas de experiência estética tecnologicamente mediadas, capazes de transformar o corpo (suas imagens, sensações e movimentos) em possibilidades de atualização dos modos de nos transformarmos e de conhecermos o mundo e os outros.

\section{O corpo que provoca acontecimentos no diálogo com a máquina}

O que acontece quando alguém entra numa instalação multimídia(1)? Segundo Diana Domingues (2001), o corpo se transforma num ator em cena, pois têm suas ações capturadas, entendidas e devolvidas por máquinas, ou seja, a plurissensorialidade do corpo se conecta às máquinas num diálogo interativo e multiplicador de devires (sensíveis e inteligíveis, humanos e maquínicos). Nas instalações multimídia as inúmeras linguagens utilizadas somam-se e permitem que os fruidores da obra se apropriem do espaço, bem como da efemeridade das informações eletrônicas de forma particular. O espaço físico da instalação, as imagens técnicas e o próprio corpo transformam-se em interfaces intercambiantes, isto é em superfícies porosas resultantes de um processo de constante diálogo. Ou seja, dentro da instalação existem vários tipos de ambientes que exigem do "experimentador" diferentes ações, percepções, intervenções. Ao mesmo tempo em que o corpo se vê atingido pelas imagens, estas, por sua vez, se alteram de acordo com a movimentação dos corpos no espaço da obra (DOMINGUES, 1998: 180).

A instalação interativa Trans-e: my body, my blood(2) expressa a preocupação que Domingues possui em encontrar um lugar para o corpo, que se vê redimensionado com a integração de novas tecnologias ao ato criativo e à própria experimentação sensível do mundo. Através da incorporação das novas tecnologias digitais ao trabalho artístico, modelos e matrizes programados conceitualmente - usando o código matemático - convertem-se em matéria sensível, e até mesmo tangível, ao interagirem com o espectador.

Guattari considera construções de todos os tipos como "máquinas enunciadoras que podem trabalhar tanto no sentido de um esmagamento uniformizador quanto na re-singularização libertadora da subjetividade individual e coletiva." (1992: 158). Desde edifícios até instalações, Guattari percebe uma íntima relação 
entre o espaço físico e o corpo. Para ele, quando o corpo se desloca dentro de um ambiente construído, ele pode desdobrar espaços de devaneio, isto é, de fazer surgir universos despertados por afetos abstratos através de uma linguagem que diz algo à memória ou ao corpo (1992: 157). Contudo, a questão principal por ele colocada é se essas máquinas de sentido são apropriadas de modo a uniformizar a experiência ou são capazes de proporcionar experiências estéticas de transformação e libertação dos sujeitos e grupos.

Nos espaços criados pelas instalações multimídia, "o corpo pode experimentar fisicamente sensações ou modulações que representam idéias teóricas" (PARENTE, 1993: 96). Isto é, o corpo está apto a interagir com espaços físicos - anteriormente preparados - e vivenciar nestes espaços experiências que exigem uma passagem entre códigos. Mais especificamente, uma passagem entre conceito e passibilidade. Afinal, para que os sentidos sejam atingidos, devem antes ser alertados pela capacidade cognitiva de decifrar o conceito chave da obra. Assim, a instalação de Domingues é muito mais conceitual que perceptiva, uma vez que exige do fruidor o entendimento das "regras do jogo" (a experiência mediada pelo inteligível). Essa pesquisadora aposta no trabalho conjunto entre a energia do corpo e a energia da máquina. Mas, será que o corpo incorporou as tecnologias digitais ou apenas se viu expandido por elas? $\mathrm{O}$ corpo atua em sinergia com a máquina ou tem sua gestualidade reduzida à uma simples ação neuromuscular?

É complicado estabelecer uma concepção de estreita hibridização entre o corpo e as máquinas. A visão da máquina como instrumento reduz o entendimento da complexidade das máquinas mulitimidiáticas que também podem atuar como um prolongamento do ato criativo. De acordo com Domingues, estamos de tal forma integrados aos sistemas eletrônicos, que tanto nosso corpo quanto nosso sangue podem ser reafirmados e amplificados através da máquina.

\section{Um ritual}

$\mathrm{Na}$ medida em que o artista concebe uma obra usando seu corpo, ele realiza uma performance: ele comunica, ritualiza e poetiza sua obra através da atividade performática de seu corpo. Quando Domingues nos oferece uma instalação como Trans-e, ela tem a intenção de tornar visível a possibilidade de um diálogo com a máquina (em suas palavras, a simbiose da vida de carbono com a vida de silício) - que se dá em uma zona elíptica ou intersticial.

Em Trans-e, somos convidados a percorrer uma caverna que tem seu chão recoberto de sensores, os quais enviam sinais dos corpos que ali se locomovem até uma rede neural(3) que interpreta os sinais e os devolvem à caverna em forma de imagens projetadas em suas paredes(4). A instalação é dividida em três ambientes da seguinte forma(5): 1) ocorrem somente sensações luminosas e mutações numa direção neurofisiológica: brilhos, cores, cintilações, flashes de luz, pontos, fusões. A mente é estimulada pelas imagens e todos têm as mesmas sensações. As imagens dependem somente do aparato biológico e não têm nenhum peso cultural ou simbólico; 2) as imagens evocam experiências pessoais e individuais armazenadas ao longo da vida. As mutações remetem a dados como religião, geografia, etnia, condição social e política e mudam de acordo com os hábitos, emoções e outras experiências individuais. Muitos mundos podem aparecer nas mentes dos participantes, 3) $\mathrm{O}$ transe acontece: imagens de fenômenos naturais aparecem misturadas a visões de vísceras e o participante pode ser induzido a experimentar sensações efêmeras e caóticas.

Os deslocamentos daqueles que experimentam a instalação são transformados em informações numéricas para que o computador as analise e as projete numa grande tela sob a forma de imagens e sons tomados de um banco de dados previamente preparado. O corpo emite sinais que, ao serem transportados e decodificados por uma máquina, dão início a um tipo de experiência estética em que a máquina intervém no processo de "afetação" do corpo pela obra. Contudo, como veremos mais adiante, é possível uma 
experiência estética da obra sem essa intervenção maquínica.

Através dessa instalação, de modo geral, Domingues busca o que Baudrillard chama de "imersão" do corpo na imagem, sendo que esta sensação é causada pela capacidade interativa e de geração em tempo real da imagem: "Imersão celular, corpuscular: entramos na substância fluida da imagem para, eventualmente modificá-la. Assim como a ciência se infiltra no código genético para transformar o próprio corpo" (BAUDRILLARD, 1997: 146).

A instalação utiliza-se das imagens e sons desencadeados pelos próprios participantes para instaurar uma espécie de transe visual e sonoro. O diálogo do corpo com a máquina, bem como os diferentes percursos realizados pelos participantes ao longo da "caverna" culminam numa espécie de performance. Nas interações com as máquinas, as formas estão em constante devir. Há uma redefinição da situação visual a partir da ação do espectador-fruidor. Em estado de virtualidade, os acontecimentos necessitam de constantes atualizações - feitas quando há interface, passagem (trânsito de códigos, corpos, sentidos) entre o biológico e o maquínico. Para Domingues (2001), esses acontecimentos se processam numa "zona intervalar" ou "intersticial" (zona de passagem), nas quais o corpo está amalgamado com a máquina mas consegue extrair o sensível do inteligível no diálogo entre memórias. Mas, segundo essa autora, uma distinção fundamental deve ser feita entre a memória da máquina e a memória humana:

O espaço da instalação se faz pelas lembranças e esquecimentos, pelas partes que retornam na mente, pelos instantes fugazes que se fazem e se desfazem na memória. (...) A memória dos dispositivos e aparelhos técnicos repete situações, enquanto nossa memória capta, repete, recria, rechaça, apaga, lembra, entrelaça as imagens como acontecimentos ou campos de possibilidades. (DOMINGUES, 1998: 185).

É preciso apontar ainda o fato de que o diálogo entre a memória da máquina e a memória humana não possui uma língua comum. Enquanto a memória humana pode recuperar experiências passadas como flashes, rastros, silêncios, imagens esmaecidas pelo tempo, a memória da máquina é digital, governada por algoritmos e cálculos. Para que houvesse um diálogo entre as duas, seria preciso uma linguagem comum. Por isso, Domingues introduz em seu trabalho o conceito de experiência xamânica (o transe xamânico é povoado de imagens e visões): a memória do fruidor é estimulada a produzir imagens a partir de imagens geradas por computadores acrescidos de redes neurais. O diálogo é travado a partir de imagens. Com uma ressalva: as imagens digitais são finitas e "sem gravidade", uma vez que estão afastadas do real. Já as imagens da memória humana têm o "peso" da significância subjetiva, ou seja, são vestígios de nosso relacionamento com o real.

A fruição do espaço da instalação só é possível quando os deslocamentos do corpo estabelecem uma trama de aproximações, afastamentos, retornos, paradas, os quais sempre produzem variadas percepções. Para Domingues (1998), esses sentidos derivam da passagem dos corpos entre os espaços de referência construídos pelos dispositivos. Assim, as imagens utilizadas nas instalações multimídia trariam a possibilidade de instituir passagens entre percepções sensoriais, memória, espaço virtual e espaço real vivido.

A instalação é, então, espaço vivo, que reage no processo de descoberta do espaço empreendido pelo corpo. Os sentidos de cada um se acham envolvidos, arrebatados pelo acontecimento no qual estão mergulhados. Ao fazer conexões com as máquinas, o corpo multiplica-se em significados, além de experimentar processos em que se inserem imprevisibilidades, dissipações e mutações: é o corpo em seu estado de imprevisibilidade. Na instalação, a experimentação é única, mesmo que o local e as imagens tenham sido anteriormente planejados. Ainda assim, poderíamos nos perguntar que tipos de acontecimentos são produzidos quando os sinais do corpo, capturados por sensores maquínicos, entram na 
máquina por meio da linguagem numérica.

Um acontecimento, segundo Quéré (2005), se constitui em uma dinâmica inesgotável de apreensões e interpretações. Nesse sentido, ele só adquire identidade e singularidade a partir do momento em que se inscreve em uma ordem social articulada pelas formas simbólicas de uma cultura. Assim, para apreendermos um acontecimento, é preciso que o transformemos em uma "unidade inteligível", isto é, precisamos situá-lo no tempo e no espaço, dar-lhe um nome, categorizá-lo, explicá-lo, conferir-lhe uma certa estrutura narrativa através do uso da linguagem (BENSA e FASSIN, 2002). Na instalação de Domingues, o corpo hipnotizado tem seus sentidos capturados, traduzidos, amplificados e devolvidos sob a forma material da imagem e do som. São as sensações humanas, misturadas às das máquinas que instauram o transe. Entretanto, não devemos entender "transe" como alienação ou hipnose, mas sim como trans-e: movimento para além de, ou através de, passagem ou per-passagem entre real e virtual, analógico e digital, sensível e inteligível.

\section{Para além da tela}

A discussão acerca da instalação de Diana Domingues abre espaço para um assunto ainda mais abrangente: o papel e o lugar do corpo - como objeto e como sujeito - dentro de formas artísticas digitais. Vimos que as tecnologias digitais possibilitam que sinais biológicos dos corpos em ação no espaço sejam capturados por dispositivos que traduzem os sinais orgânicos em paradigmas computacionais. Antes de mais nada, devemos nos lembrar que muitos aspectos da realidade virtual e conceitos como interatividade, processo, co-participação, imersão e experenciação vieram da arte e não da comunidade científica.

Desde os anos 50 e 60(6), os artistas passaram a pensar suas obras em interseção com os espectadores. Lygia Clark e Hélio Oiticica, por exemplo, criaram, entre as décadas de 60 e 70, vários instrumentos, dispositivos ou interfaces sensoriais (luvas, máscaras, óculos, capuzes, casacos, vestimentas, etc.) capazes de "reverberar" e virtualizar os sentidos. Um exemplo de uso desses acessórios pode ser visto na obra de Lygia Clark, Nostalgia of the body (7) (1964-1968). Nesse trabalho, a participação do espectador fica em primeiro plano, enquanto o objeto torna-se secundário, isto é, existe somente para promover uma experiência sensorial. Para Clark e Oiticica, a participação do espectador deveria basear-se no total envolvimento do corpo (mente, sentidos, espaço interno e externo ao corpo) no processo de experimentação da obra de arte. A contribuição desses dois artistas está além da associação entre a produção artística, o momento sócio-cultura e a estética, pois expressa o legado da exploração de uma linguagem que comporta os resultados de experimentos com objetos manipuláveis, ambientes imersivos (geralmente instalações interativas) e propostas experenciais baseadas em obras feitas para serem vestidas.

De acordo com Osthoff, a trajetória artística de Clark pode ser definida como uma constante passagem da "arte do objeto" à "arte da participação" ou "from form to experience" (1997: 281). Sob esse aspecto, Clark deixa de lado o objeto para se concentrar na participação do espectador como foco principal de seus trabalhos, reconhecendo neles a "coexistência de opostos no mesmo espaço: interno e externo, subjetivo e objetivo, metafórico e literal, masculino e feminino” (OSTHOFF, 1997: 282).

Lygia Clark considerava os participantes de suas obras como "sujeitos em processo". Suas obras tendiam para uma reestruturação do ser através de uma linguagem pré-verbal, ou seja, uma linguagem exploratória (de re-descobrimento) de texturas, sons, peso, temperatura, som e movimento. Enfatizando o "aqui e agora" bem como o fluxo contínuo do tempo, as obras de Clark são verdadeiras "máquinas de devir", sendo constantemente redefinidas por cada participante. Objetos feitos de materiais simples, como areia, 
água, borracha, pedras, conchas e ar só tinham sentido quando "em relação" com os participantes.

Em suas obras, Hélio Oiticica explora a sensorialidade das cores associando-as a fatores como tempo, espaço e forma. Durante a década de 60, Oiticica realizou trabalhos que convidavam os espectadores a se tornarem participadores, instigando-os a percorrerem o espaço dos sentidos. As palavras de ordem eram: vestir, tocar, cheirar, ouvir, ver, mover. Semelhante a um labirinto sinestésico (BRAGA, 2008), sua obra, assim como a de Clark, se dá em função de espaços híbridos (instauração, performance, instalação), nos quais deve haver um movimento de "passagem", de trans-posição e fluxo.

Foi com os Parangolés (segunda metade da década de 60) que Oiticica envolveu o corpo na arte interativa da performance, fundindo corpo e espaço através do movimento e do ritmo. Espécie de túnicas ou capas, os parangolés foram inspirados nas cores e sons da Escola de Samba da Mangueira, da qual o artista fez parte. Associando comportamento, sensualidade e gestualidade em movimentos que proporcionavam àqueles que vestiam os parangolés uma sensação de fluxo de energia entre espaçocorpo-tempo, promovendo verdadeiras interfaces do corpo com o ambiente e a música. Eles não têm status se não são vestidos, usados, "habitados", pois foram feitos para serem vividos, experimentados (JACQUES, 2008).

"Vestir" o Parangolé ou uma interface de computador (ou o ambiente que aparentemente está por trás dele) é misturar corpo e tecnologia, a fim de alterar ou extender o corpo e a socialidade, de modo a integrar os sujeitos, corpos e formações sociais em um processo de construção e habitação do espaço (OSTHOFF, 1997: 286)

Nos anos 70, a body-art atinge seu ponto máximo: muitos artistas deslocam seus trabalhos para o vídeo de modo a proporcionar um tipo de dissolução do corpo nas fitas magnéticas. Intensifica-se a exploração tecnológica do corpo, na qual ele é visto como limite a ser superado. O corpo-signo e as sensações por ele experimentadas nos anos 60 (body-art, body-piercing, performance, etc.) divide agora espaço com o corpo-prótese, isto é, um corpo extendido, potencializado, virtualizado (LÉVY, 1996).

\section{Interfaces corpo-máquina}

Desde que a biotecnologia conseguiu tornar visíveis imagens de locais os mais insuspeitos do interior do corpo (raios X, ultra-sonografia, nanotecnologia, etc.) muitos artistas começaram a explorar a superfície do avesso do corpo em seus trabalhos.

Nessa linha, podemos apontar as performances do australiano Stelarc, que engolia capsulas que se transformariam em esculturas dentro de seu próprio estômago (esse artista crê na obsolência do corpo e acredita na técnica como possibilidade de suplantá-lo). Podemos também citar, embora invistam em experiências de outra natureza, Diana Domingues, que se apropriou de imagens de radiografias e ultrasonografias para produzir The reverse side of the body (1996)(8) e David Rokeby, que utiliza o computador em Very Nervous System (1986-1990)(9) para capturar gestos e movimentos do corpo e transformá-los em sons ou músicas (corpo sonoro).

Há aqui que se considerar no mínimo duas situações: a virtualização do corpo e a fabricação do corpo protético. Ambas dizem respeito ao corpo em seu estado virtual mas, enquanto a primeira enfatiza a hibridação entre corpo e imagem, a imersão dos sentidos e a construção de sensações no ciberespaço, onde "cada corpo individual torna-se parte integrante de um imenso hipercorpo mundializado" (LÉVY, 1996: 32); a segunda mostra o corpo "esticado" e invadido por máquinas - como na obra de Sterlac, que transforma seu corpo em um emaranhado de parafernálias eletrônicas (design maquínico do corpo), esperando que ele opere e exista em sua capacidade máxima (o corpo transformado em projeto de 
engenharia). A trajetória performática de Stelarc vem seguindo dois caminhos(10): o primeiro reforça as potencialidades do corpo a serem amplificadas pelos dispositivos técnicos. O segundo caminho, mais radical, enfatiza propostas de total reorganização ou reconstrução do corpo (1997). Stelarc investe, então na criação de um novo corpo, capaz de não só desafiar a morte, como também de modificar, com o auxílio da nanotecnologia, a trajetória existencial de uma vida (CAYGILL, 1997: 48).

Diferentemente de Sterlac, o trabalho do artista canadense David Rokeby não procura trazer a máquina para dentro do corpo, mas busca alternativas capazes de fazer com que o computador retire os sujeitos fruidores de seus corpos. Nesse caso, não só o fruidor se vê alterado ao passar pela experiência interativa, mas também a própria estrutura física da obra é redimensionada, reformulada, atualizada. Uma das obras mais conhecidas de Rokeby, Very Nervous System (1986-1990), visa produzir acontecimentos sinestésicos capazes de extrair a poética da instalação (espaço e tempo como pressupostos sensoriais da ocorrência dos objetos para nós). Dito de outro modo, a obra de Rokeby tenta atualizar formas que flutuam livremente no espaço e no tempo a partir de propostas sensorias que delimitam o espaço e o tempo da ocorrência dos objetos para nós (GUIMARÃES, 2002b).

Em Very Nervous System as imagens do corpo, que dança no interior da instalação, são observadas por uma câmera de vídeo. Um computador compara cada quadro com o anterior para definir o que está se movendo. Essa informação é transformada em som por um programa de software. Os sons são ouvidos quase simultaneamente aos movimentos que produzem.(11) O resultado é uma inversão na relação tradicional entre dança e música. Rokeby se preocupou em pensar modos diferentes de explorações poéticas de seu invento, bem como em tornar a experiência interativa mais intuitiva. Sua proposta distancia-se daquela de Diana Domingues, a partir do momento em que ele propõe que o corpo se encontre com a máquina num espaço por ele já habitado, ou seja, seu espaço cotidiano.

A passibilidade proporcionada pelo aqui agora é reforçada por Rokeby, pois Very Nervous Systemnão é a manifestação de situações possíveis controladas por uma matriz lógica. Os desdobramentos da obra e as descobertas feitas por seus fruidores resultam de ações não previstas, de sensações oriundas de um diálogo homem-máquina-espaço-físico da ordem de uma apresentação, não de uma representação. Rokeby aposta na força contemplativa do olhar. O olhar que tudo capta, que traduz movimentos em sons, que permite a passagem entre códigos em tempo real. Domingues aposta na imersão do corpo dentro das imagens (no transe) e na produção sintética do espaço e do tempo da experimentação. Já Rokeby quer o corpo cada vez mais desperto, ansioso pelo inusitado. Em Very Nervous System o olho da câmera capta variações da intensidade da luz provocada pelos movimentos sutis que ocorrem ao seu redor. Mas tanto a obra de Domingues quanto a de Rokeby possuem apenas uma parte armazenada de "possíveis", sendo a outra parte composta pelos virtuais que se atualizam no momento mesmo da interação. O controle maquínico sobre o resultado da interação nunca é total, daí o resgate da experiência estética.

Ao levar Very Nervous System para as ruas, Rokeby aposta no envolvimento dos passantes que, para poderem interagir com a obra, devem diminuir a velocidade do caminhar e entregar-se ao tempo de fruição, à finitude sensível do acontecimento. O tempo de fruição da obra nos coloca em contato com elementos que passariam despercebidos na sequência de realização da rotina cotidiana: os sons, os movimentos do corpo, a auto-descoberta, a percepção dos outros e as inúmeras possibilidades de estabelecer "passagens" entre diferenças. A experiência proporcionada pelas formas de arte digitais nos oferece, então, a oportunidade de

Produzir novos infinitos a partir de um mergulho na finitude sensível, infinitos não apenas carregados de virtualidade, mas também de potencialidades atualizáveis em situação, se demarcando ou contornando todas as coisas que implicam a promoção permanente de outros agenciamentos enunciativos, outros recursos semióticos, uma alteridade apreendida em sua 
posição de emergência (...), devires intensivos e processuais, um novo amor pelo desconhecido (GUATTARI, 1992: 147).

A experiência interativa tem um momento que nos carrega para dentro da vida, ou para dentro de novos espaços criados a partir do contato com a obra. Mas tal experiência também (re)constroi espaços em que somos convidados a "perceber fisicamente um modelo teórico e compreender formalmente as sensações físicas" (QUÉAU, 1993: 97). Assim, ao invés de apostarmos em uma "nostalgia do corpo", talvez, como salientou Oiticica, seja mais promissor buscar compreender como o corpo lida com o desejo do indeterminado e com novas formas de experimentar o mundo, a si mesmo e ao outro.

\section{Considerações finais}

Diante das reflexões aqui desenvolvidas, reconhecemos que a virtualização do corpo não é da ordem de uma desmaterialização e sim de uma problematização. $\mathrm{O}$ corpo virtualizado está apto a percorrer um espaço de troca, de deriva, ao mesmo tempo em que se torna passagem, devir (do interior ao exterior, por exemplo). Vetor do duplo devir-deriva, o corpo é sujeito e objeto de acontecimentos que afloram na relação dialógica entre corpo e máquina. O diálogo homem-máquina, no domínio do digital, se dá de forma predominantemente visual. São as imagens de síntese que estabelecem "ligações inéditas entre preceitos e conceitos, entre fenômenos perceptíveis e modelos inteligíveis."(QUÉAU, 1993: 94).

Em sua missão exploratória da topologia do ciberespaço, o corpo é decomposto em partes sensíveis. Seus gestos são contaminados pela imersão dos sentidos nas imagens técnicas (incluindo textos e sons). Desta forma, o acesso que o fruidor tem à obra não é apenas via gestos mecanicistas, pois este fruidor interfere na obra via percepção sensível do modelo que ele está percorrendo, experimentando e atualizando. Sobre esse aspecto, Parente levanta uma questão fundamental: "devemos nos conformar com um novo corpo que se nos emprestam, como uma roupa de dados que determina as possibilidades de uma ação já programada?" (1993: 29). Assim, a experiência estética que envolve a participação do corpo nas formas de criação digitais não pode se restringir apenas à descrição do que está acontecendo, ou à descrição de respostas a estímulos já previstos. Ao invés disso, a experiência estética é da ordem do imprevisível. Ela se produz como "devir", servindo-se justamente da não-predictabilidade dos contatos entre "eu e a obra", "eu e o outro", "fenômenos sensíveis e interpretações cognitivo-racionais".

O corpo virtual e fluido é uma transdução do corpo físico. Segundo Plaza (1987), o processo de transdução consiste em fazer com que as máquinas traduzam os "inputs" criativos do indivíduo que está agindo sobre determinados espaços, de modo que sua percepção reconstrua o sentido ou o objeto. Sob esse viés, a sensorialidade se projeta para além da pele, vetorizando-se e reconfigurando-se "no campo eletromagnético do circuito, no domínio da imagem" (STERLAC, 1997: 62). A estética digital está relacionada a uma sensorialidade do porvir, com uma maneira híbrida (entrelaçamento do sensível e do inteligível) de interagir com a realidade e de viver num determinado tempo e espaço.

A tecnologia não é uma simples extensão ou continuidade do indivíduo, mas sim um dos elementos, um devir do humano. A serviço da arte e da concepção de novas poéticas digitais, a tecnologia tem a tarefa de instaurar uma zona de hibridação, um espaço intersticial de passagem "que faz a dobra do humano/nãohumano, desterritorializando nossa percepção antes de reconectá-la à outros possíveis.” (COSTA, 1997: $65)$.

A matriz lógica que origina os produtos artísticos e informacionais da era do digital nos suscita várias dúvidas a respeito da natureza da experiência estética tecnologicamente mediada. Para Lyotard, "ao tornar o sensível mediado pelo entendimento, a tecnociência substitui a possibilidade por uma atividade baseada na reação diante de uma situação calculada" (1993: 262). Se considerarmos verdadeira a afirmação de 
Lyotard, podemos duvidar da possibilidade de uma experiência estética produzida a partir de uma interface homem-máquina, pois esta, assim como a comunicação, não resume a respostas imediatas a estímulos calculados, mas exige uma interlocução entre o sensível e o inteligível, a imediaticidade da experiência e a mediaticidade dos procedimentos técnicos, uma conexão entre o auto-entendimento e o entendimento do outro, entre o culturalmente familiar e o estranhamento, permitindo a emergência do inusitado.

Assim, o desafio enfrentado pelas formas de arte digitais é a criação de dispositivos que não reduzam o corpo a um conjunto de sinais emitidos e matematizados pelas máquinas. É preciso investir em mecanismos que privilegiem estranhamentos, pois a força da experimentação não pode ser criada ou mesmo antecipada ao momento da experiência, no qual o corpo é arrebatado pela obra e colocado em contato com diferentes universos, linguagens e alteridades.

\section{Bibliografia:}

Arte e tecnologia. [Editor] Instituto Cultural Itaú. Apresentação de Ricardo Ribenboin. São Paulo: ICI, 1997.

ASCOTT, Roy. "Is there love in the telematic embrace?". Art Journal. New York, v. 49, n.3, 1990, p. 241-247.

ASCOTT, Roy (ed.). Art, Technology, Consciousness. United Kingdom: Intellect Books, 2000.

BAUDRILLARD, Jean. Tela-Total: mito-ironias da era do virtual e da imagem. Porto Alegre: Sulina,1997.

BENSA, A.; FASSIN, E. “Les sciences sociales face à l'événement”. Terrain. Paris, n. 38, p. 5-20.

BRAGA, Paula (Org.). Fios soltos: a arte de Hélio Oiticica. São Paulo: Perspectiva, 2008.

CAUNE, Jean. Esthétique de la Communication. Paris : Presses Universitaires de France, 1997.

CAYGILL, Howard. "Stelarc and the Chimera: Kant's critique of Prosthetic Judgment", Art Journal, New York, spring 1997, p. 46-51.

COSTA, Mário. “Corpo e Redes”. In: DOMINGUES, Diana (org). A arte no século XXI - a humanização das tecnologias. São Paulo: Fundação Editora da UNESP, 1997, p. 303-314.

COSTA, Rogério da. "Do tecnocosmos à tecno-arte". In: DOMINGUES, Diana (org). A arte no século XXI - a humanização das tecnologias. São Paulo: Fundação Editora da UNESP, 1997, p.63-66.

COUTO, Edvaldo Souza. "Estética e virtualização do corpo”. Fronteiras. São Leopoldo, v. 1, p. 63-76, 1999.

DOMINGUES, Diana (org). A arte no século XXI - a humanização das tecnologias. São Paulo: Fundação Editora da UNESP, 1997.

DOMINGUES, Diana. Trans-e: my body, my blood. Catálogo da instalação interativa. ISEA 97, XVIII 
Simpósio Internacional Society for the Eletronic Arts, Chicago, USA, 1997, p. 58-59.

DOMINGUES, Diana. "As instalações multimídia como espaços de dados em sinestesia”. In: FECHINE, Y. \& OLIVEIRA, A. (orgs.). Imagens Técnicas. São Paulo: Hacker Editores, 1998, p. 179-204.

DOMINGUES, Diana. “Tecnologias, produção artística e sensibilização dos sentidos”. In: PILLAR, Analice Dutra (Org.). A educação do olhar no ensino das artes. Porto Alegre: Mediação, 2001, p. 37-70.

GUATTARI, Felix. Caosmose: um novo paradigma estético. Rio de Janeiro: Ed.34,1992.

GUIMARÃES, César. "O campo da comunicação e a experiência estética”. In:WEBER, M. et alli (org.). Tensões e objetos da comunicação. Porto Alegre: Sulina, 2002a, p.83-100.

GUIMARÃES, César. "O novo regime do visível e as imagens digitais”. In: CASA NOVA, Vera; VAZ, Paulo (Orgs.). Estação Imagem. Belo Horizonte: Ed. UFMG, 2002b, p. 147-161.

GUIMARÃES, César; FRANÇA, Vera. "Experimentando as narrativas no cotidiano”. In: Na Mídia na Rua: narrativas do cotidiano. Belo Horizonte: Autêntica, 2006. (orgs.).

HUCHET, Stéphane. “Instação, alegoria, discurso”. Trilhas. Campinas, v. 6, n. 1, p. 66-76, 1998.

JACQUES, Paola. "Parangolés de Oiticica/ Favelas de Kawamata". In: BRAGA, Paula (Org.). Fios soltos: a arte de Hélio Oiticica. São Paulo: Perspectiva, 2008, p.153-162.

KERCKOVE, Derrick de. "O senso comum, antigo e novo". In: PARENTE, André (org.). ImagemMáquina: a era das tecnologias do virtual. Rio de Janeiro: Ed.34, 1993, p.56-64.

LAGNADO, Lisette. "Longing for the Body", no catálogo da mostra "Brazil, Body Nostalgia", no Museu de Arte Moderna de Tóquio, em junho/2004.

LÉVY, Pierre. O que é o virtual? São Paulo: Ed.34, 1996.

LYOTARD, Jean-François. “Algo assim como comunicação... sem comunicação.” In: PARENTE, André (org.). Imagem-Máquina: a era das tecnologias do virtual. Rio de Janeiro: Ed.34, 1993, p.258-266.

OSTHOFF, Simone. "Lygia Clark and Hélio Oiticica: a legacy of interactivity and participation for a telematic future”. Leonardo. San Francisco, v.30, n. 4, 1997, p. 279-289.

PARENTE, André (org.). Imagem-Máquina: a era das tecnologias do virtual. Rio de Janeiro: Ed.34, 1993.

PLAZA, Júlio. Tradução Intersemiótica. São Paulo: Perspectiva/ CNPq, 1987.

QUÉAU, Philippe. "O tempo do virtual”. In: PARENTE, André (org.). Imagem-Máquina: a era das tecnologias do virtual. Rio de Janeiro: Ed.34, 1993, p.91-99.

QUÉRÉ, Louis. Entre facto e sentido: a dualidade do acontecimento. Trajectos. Lisboa, n. 6, 2005, p. 5975.

STERLAC. "Das estratégias psicológicas às ciberestratégias: a protética, a robótica e a existência 
remota”. In: DOMINGUES, Diana (Org.). A arte no século XXI - a humanização das tecnologias. São Paulo: Fundação Editora da UNESP, 1997, p.45-48.

\section{Notas:}

(1) Para Stéphane Huchet, "a instalação, enquanto dispositivo ao mesmo tempo de espalhamento do sentido, de concentração e condensação discursivas, surge diante de nós como esboço e agenciamento do sentido." (1998: 75).

(2) Esta instalação foi montada pela primeira vez em 1997 para figurar entre os trabalhos apresentados no Oitavo Simpósio da International Society for The Eletronica Arts of Chicago (ISEA). Em 1998, a instalação foi para a Galeria de Arte da Universidade de Caxias do Sul (GAU).

(3) “As redes neurais não são máquinas que calculam, mas máquinas que interpretam. (...) Acrescentando-se uma rede neural a um micro ele é transformado numa prótese inteligente. As redes neurais podem funcionar com ou sem tratamento digitalizado, mas seu objeto e seu método de aplicação consistem em medir continuidade, e não unidades discretas. As redes neurais devem julgar, coisa que a inteligência artificial ou os sistemas especializados não precisam fazer.” (KERCKOVE, 1993: 62).

(4) Domingues explica sua proposta: "Para estimular o ritual do transe, o som de um tambor repete um ritmo insistente e o som de batidas de um coração é alterado pelo calor dos corpos em ação. Simultaneamente, um líquido vermelho (simulando sangue) dentro de uma bacia move-se também pelo efeito das ondas infravermelhas que conectam o calor dos corpos. (...) Ao interagir, as pessoas trocam forças invisíveis com sistemas artificiais. As mutações das sequiências de imagens e sons resultam do comportamento do visitante captado pela sensibilidade dos sensores instalados no chão, que transmitem os sinais do corpo às máquinas. As variáveis que determinam o comportamento da rede são: onde você está, por quanto tempo você permanece e quantas pessoas se encontram sobre o tapete sensorializado. Assim, as redes neurais apreendem alguns padrões do comportamento dos participantes, manipulam esses dados e provocam visões na sala em uma experiência enigmática de TRANS-E." (Cf. Catálogo da Instalação TRANS-E, 1997).

(5) Ver o Catálogo da exposição Arte e Tecnologia, do Itau Cultural, 1997.

(6) "Nos anos 50, as várias declinações da action-painting e do gestualismo põem novamente em primeiro plano o corpo e exibem uma pintura cujo sentido forte é aquele de salientar que a superfície trabalhada e oferecida à vista é o resultado de um trabalho muscular e que, onde agora existem os signos, lá existiu um corpo. (...) O corpo não fala mais real e diretamente de si, mas apresenta-se na forma de um corpo que se dá somente como 'já sido' e como ausência. Ao corpo implícito do gestualismo sucede o corpo explícito da body-art. (COSTA, 1997: 307)

(7) Para Hélio Oiticica, o termo "nostalgia" seria inapropriado para caracterizar a intenção do trabalho de Clark. "Nostalgia" é, para ele, um termo comprometido com uma anterioridade inalcançável (a imagem do paraíso perdido); denota trauma e melancolia. Ele explica que a expressão longing for the body corresponde melhor às pesquisas de Clark, porque abre o corpo para aquilo que está por vir, para o desconhecido e para o indeterminado. Essa expressão distancia-se da perda e da falta, que remetem os sujeitos a uma felicidade localizada no passado e, portanto, irrecuperável (LAGNADO, 2004).

(8) Ver a série de páginas que se iniciam no link: < http://www.arte.unb.br/netlung/diana/diana3.htm>. 
(9) Ver o link: < http://homepage.mac.com/davidrokeby/vns.html>.

(10) Ver o site: < http://www.stelarc.va.com.au/>.

(11) Ver o site: < http://homepage.mac.com/davidrokeby/vns.html>.

\section{Mini Currículo :}

Doutora em Comunicação Social pela UFMG e Professora do Programa de Pós-Graduação em Comunicação Social da Faculdade Cásper Líbero (SP). 